\title{
Perbedaan Pandangan Politik antara Al Azhar dan Ikhwan Al Muslimin dalam Merespon Kudeta Militer Tahun 2013'
}

\author{
Muhammad Anas, Yon Machmudi \\ Prodi Kajian Wilayah Timur Tengah dan Islam, Sekolah Kajian Stratejik dan Global Universitas \\ Indonesia \\ e-mail: yonmachmudi@yahoo.com
}

\section{Abstract}

This articles discusses the political differences between Al Azhar and the Muslim Brotherhood (Ikhwan Al Muslimin) in a coup against President Mohammed Morsi on July 3, 2013. It is interesting that Al Azhar as one of the most influential religious institutions in the Islamic world in general and Egypt in particular, supporting the military coup led by General Abdul Fattah al-Sisi against Morsi, the first president of Egypt's who was democratically elected and also promoted by the largest Islamic movement in the 21st century, namely the Muslim Brotherhood. Previous studies have not been yet specifically discussed the differences between these two institutions in this coup. This study uses qualitative methods named causal explanation which seeks to explain the causes of the observed phenomena. The method of data analysis is content analysis of various documents related to the research topic. The data was collected by literature studies and interviews. This articles found that both Al Azhar and Ikhwan Al Muslimin have a significant different view on politics even though historically both also have close relationship in developing religious acitivities in Egypt. Al-Azhar Institution in this context loses its independence which encourages its involvement in conflicts between the state and Ikhwan Al Muslimin. In general,

$1 \quad$ Artikel ini merupakan hasil penelitian yang didanai oleh hibah Publikasi Internasional Terindeks untuk Tugas Akhir (PITTA) 2016, Direktorat Riset dan Pengabdian Masyarakat Universitas Indonesia (DRPM UI). 
the political relationship between the two institutions is largely determined by the relationship between Ikhwan Al Muslimin and the ruling regime.

Keywords: Al Azhar, Egypt, military coup, Muslim Brotherhood, political conflict

\section{Abstrak}

Artikel ini membahas perbedaan politik antara Al Azhar dan Ikhwan Al Muslimin dalam menyikapi kudeta terhadap Presiden Mohammed Morsi pada 3 Juli 2013. Sangat menarik untuk diamati, Al Azhar sebagai salah satu lembaga keagamaan paling berpengaruh di dunia Islam pada umumnya dan Mesir pada khususnya, mendukung kudeta militer yang dipimpin oleh Jenderal Abdul Fattah Al Sisi terhadap Morsi, presiden pertama Mesir yang terpilih secara demokratis dan juga dipromosikan oleh gerakan Islam terbesar di abad ke-21, yaitu Ikhwan Al Muslimin. Belum ada penelitian yang secara khusus membahas perbedaan antara kedua lembaga ini dalam menyikapi kudeta terhadap presiden Mursi. Penelitian ini menggunakan metode kualitatif bernama penjelasan kausal yang berupaya menjelaskan penyebab fenomena yang diamati. Metode analisis data yang digunakan dalam penelitian ini adalah analisis konten yang dilakukan terhadap berbagai dokumen yang berkaitan dengan topik penelitian. Peneliti menggunakan metode pengumpulan data dalam bentuk literatur dan wawancara. Artikel ini menemukan bahwa baik Al Azhar maupun Ikhwan Al Muslimin memiliki perbedaan pandangan yang signifikan tentang politik walaupun secara historis keduanya juga memiliki hubungan yang erat dalam mengembangkan kegiatan keagamaan di Mesir. Institusi Al-Azhar dalam konteks ini kehilangan independensi yang mendorong keterlibatannya dalam konflik antara negara dan Ikhwan Al Muslimin. Secara umum, hubungan politik di antara kedua institusi itu sangat ditentukan oleh hubungan antara IM dan rezim penguasa.

Kata Kunci: Al Azhar, Ikhwan Al Muslimin, kudeta militer, Mesir, konflik politik

\section{Pendahuluan}

Al Azhar dan Ikhwan Al Muslimin (IM) adalah dua institusi penentu proses demokratisasi dan transformasi di Mesir. Tanpa keduanya, tegaknya sistem politik yang menjamin kebebasan, proses pergantian kekuasaan, pengakuan eksistensi kelompok lain akan sulit terwujud. Masyarakat Mesir akan senantiasa berada 
dalam bayang-bayang penguasa otoriter dan militer tanpa kedua institusi ini (Hasan, 1995:7). Gerakan-gerakan Islam di Mesir dengan beragam bentuknya, baik tradisionalis maupun modernis juga tak lepas dari pengaruh dua institusi ini. Gerakan Islam tradisionalis dipengaruhi oleh peran ulama-ulama Al Azhar, seperti Jamiyah Syariah dan Jamaah Anshar Sunnah sementara gerakan-gerakan Islam kontemporer seperti Jamaah Islamiyah, Jamaah Takfir wa al-Hijrah, Hizb al-Tahrir dan Jamaah Jihad tak lepas dari pengaruh IM (Rashed, 2016).

Menurut Muhammad Imarah, salah seorang pemikir kritis Al Azhar, IM dan Al Azhar secara manhaj dan pemikiran memiliki kesamaan. Bahkan Imarah menyebutkan bahwa IM adalah orang-orang Al Azhar yang melakukan pembaharuan dan kelanjutan dari madrasah Muhammad Abduh, pembaharu Al Azhar, di mana Rasyid Ridha guru Hasan Al-Banna (pendiri IM) adalah murid dari Muhammad Abduh (wawancara dengan Imarah, 20 September 2016). Tidak heran jika banyak ulama Al Azhar yang kemudian bergabung dengan IM, seperti Syaikh Muhammad al-Gazali, Syaikh Bahi Khuly, dan Syaikh Yusuf al-Qardhawi. Muhammad Imarah menyebutkan jumlah ulama Al Azhar yang berafiliasi ke IM pasca revolusi 2011, mencapai 40.000 orang yang tergabung dalam asosiasi dai (wawancara dengan Imarah, 20 September 2016).

Al Azhar mencapai kegemilangan di masa Dinasti Mamalik dan Usmani dan faktor penyebab kegemilangan ini antara lain adalah independensi finansial Al Azhar, independensi keilmuan Al Azhar, kedudukan ulama Al Azhar di tengah masyarakat, dan perhatian rezim penguasa kepada Al Azhar (Majidah, t.t.: 277280). Pasca Revolusi Juli 1952, Al Azhar berada dalam kontrol rezim penguasa militer, melalui undang-undang reformasi tanah (Land reform law tahun 1952) (Moustafa, t.t.:4-5), penghapusan Mahkamah Syariah tahun 1955 (Munib, 2010:39), dan nasionalisasi Al Azhar pada tahun 1961 (Munib, 2010:42). Kontrol rezim secara otomatis mempengaruhi sikap dan pandangan-pandangan Al Azhar, termasuk ikut menyerang IM melalui Syaikh Al Azhar (Majidah, t.t:302).

Pasca tumbangnya Husni Mubarak dalam revolusi 25 Januari2011, IM memenangi pesta demokrasi dengan perolehan 45,2\% pada pemilu parlemen dan 51,7\% pada pemilihan Presiden Mesir, dengan mencalonkan Muhammad Mursi (Basyar, 2015:12). Naiknya Mursi menjadi Presiden memunculkan sejumlah ekspektasi, di antaranya, Al Azhar dan IM akan memasuki fase baru persatuan. Namun dalam perkembangannya, kedua institusi ini terlibat dalam perbedaan politik yang mengarah pada konflik, khususnya dalam kudeta terhadap Presiden Mursi pada 3 Juli 2013. Al Azhar ikut mendukung kudeta yang dipimpin rezim militer dengan pertimbangan memilih 
bahaya mudharat yang lebih ringan di antara dua bahaya yang ada (ahaffu aldhararain).

Dalam artikel ini, akan dibahas mengenai bagaimana hubungan antara Al Azhar dan IM dengan penguasa Mesir, serta mengapa terjadi perbedaan sikap politik antara Al Azhar dan IM dalam kudeta militer terhadap Mursi tahun 2013. Struktur artikel dibagi ke dalam 5 bagian yaitu pendahuluan; metodologi dan landasan teori; hubungan antara Al Azhar, Ikhwan Al Muslimin, dan penguasa; respon Al Azhar dan IM terhadap Revolusi 2011; Al Azhar, IM, dan kudeta militer 2013; dan diakhiri dengan kesimpulan.

\section{Metodologi dan Landasan Teori}

Metode yang digunakan dalam penelitian ini adalah metode kualitatif dengan pendekatan studi causal explanation. Penelitian dilakukan di Mesir pada tanggal 9-25 September 2016 dalam bentuk observasi dan wawancara. Wawancara dilakukan secara langsung di Kairo dengan Muhammad Imarah, intelektual Al Azhar dan Rafiq Habib, mantan Wakil Presiden Freedom and Justice Party (FJP). Selanjutnya, peneliti menggunakan sumber-sumber sekunder yang terdiri dari buku-buku di perpustakaan, data-data dari koran, dan artikel majalah serta jurnal ilmiah. Sumbersumber tersebut diseleksi menurut kategori atau subjek terkait sehingga membantu peneliti dalam menganalisis permasalahan secara maksimal.

Dalam hal teori, penelitian ini menggunakan teori konflik Dahrendorf yang memusatkan perhatiannya pada struktur sosial yang lebih besar, yang menjadi intinya adalah bahwa berbagai posisi dalam masyarakat memiliki jumlah otoritas yang berbeda. Dahrendorf tidak hanya tertarik pada struktur pada posisi-posisi ini, namun juga pada konflik di antara mereka. Bagi Dahrendorf tugas pertama analisis konflik adalah mengidentifikasi beragam peran otoritas dalam masyarakat. Dahrendorf menentang mereka yang memusatkan perhatian pada level individu. Otoritas yang melekat pada oposisi adalah elemen kunci dalam analisis Dahrendrof. Aspek terakhir dalam teori Dahrendorf adalah hubungan konflik dengan perubahan, dalam hal ini Dahrendorf mengakui pentingnya pemikiran Louis Coser, yang memusatkan perhatian pada fungsi kelompok dalam mempertahankan status quo, tetapi Dahrendorf menganggap fungsi konservatif dan konflik hanyalah satu bagian dari realita sosial, konflik juga menyebabkan perubahan dan perkembangan (Ritzer, 2008: 285). 
Otoritas secara tersirat menyatakan superordinasi dan subordinasi. Mereka yang menduduki posisi otoritas diharapkan mengendalikan bawahan. Artinya mereka berkuasa karena harapan ataupun pilihan dari orang-orang di bawah mereka, bukan karena kekuatan mereka sendiri. Otoritas bukanlah fenomena sosial yang umum, layaknya hukum, mereka yang dapat mematuhinya terlepas dari sanksi ataupun sebaliknya, yang membedakannya adalah hukum mempunyai sanksi yang tegas dan mengikat dibanding otoritas (Ritzer, 2008: 283).

Konflik yang terjadi antara Al Azhar dan IM muncul akibat adanya perbedaan pendapat mengenai jalan keluar atas situasi politik yang terjadi di Mesir. IM yang mengusung Presiden Mursi menganggap kudeta yang dilakukan oleh Abdul Fattah Al Sisi sebagai penghianatan terhadap legitimasi rakyat Mesir yang telah memilih Presiden Mursi. Di satu sisi Al Azhar ikut mendukung kudeta yang terjadi. Hal inilah yang memicu Al Azhar masuk dalam konflik dengan IM. Kudeta militer ini menimbulkan banyaknya kerusakan secara material dan korban jiwa. Konflik ini menyebabkan sebuah perubahan dalam masyarakat, seperti dalam komunikasi antar anggota masyarakat yang berbeda kelompok. Hubungan antara Al Azhar dan IM mengalami pasang surut dan berujung pada konflik secara tidak langsung pasca lengsernya Mursi dari posisi kepresidenen terutama karena Al Azhar menunjukkan dukungannya kepada kudeta militer yang dilakukan oleh AI Sisi.

\section{Hubungan antara Al Azhar, Ikhwan Al Muslimin, dan Penguasa}

Ikhwan Al Muslimin (Jam'iyyyat al-Ikhwan al-Muslimin) didirikan oleh Hasan Al Banna pada tahun 1928 sebagai respon dari masalah sosial ekonomi yang dihadapi masyarakat Mesir pada masa itu, yang terutama disebabkan oleh kuatnya dominasi asing dalam mengeksploitasi kekayaan bangsa Mesir. Dalam waktu singkat, IM berkembang luas dan banyak mendapatkan anggota karena tiga faktor, yaitu pelayanan sosial dan ekonomi yang diberikan kepada masyarakat, gerakan perlawanan terhadap rezim, dan perjuangan membela Palestina pasca didirikannya Israel pada tahun 1948 berdasarkan Resolusi PBB 181/1947 (Mamdud, 2018).

Sementara itu, Al Azhar didirikan jauh sebelumnya, yaitu pada tahun 972. Pada awalnya, menurut Majidah (t.t.: 265) Al Azhar dijadikan sebagai mimbar untuk menyebarkan ideologi Syiah, di mana Jauhar al-Siqily, panglima Dinasti Fatimiyah mendirikan Al Azhar pada tahun 361 H / 972 M dengan tujuan strategis yaitu menyebarkan mazhab Syiah di tengah masyarakat Mesir yang bermazhab Sunni. Setelah keruntuhan Dinasti Fatimiyah di tangan Shalahuddin Al Ayubi (567 H / 1169 
M), menurut Khafaji (2006:84), Shalahuddin berusaha menghapus jejak-jejak Syiah dan menggantikannya dengan mazhab Sunni. Shalahuddin juga menutup masjid Al Azhar yang dijadikan tempat shalat Jumat. Penutupan ini berlangsung selama sekitar seratus tahun lamanya, mulai dari tahun 567 hingga tahun 665 Hijriah (1169-1276 M). Al Azhar mulai kembali aktif di masa Dinasti Mamalik dan mencapai kegemilangannya pada masa Dinasti Mamalik (648-922 H) (1250-1517 M) dan masa Turki Usmani (922-1250 H / 1517-1805 M).

Pada tahun 1840-1952, ketika Mesir dikuasai Dinasti Muhammad Ali, yang dipimpin oleh Abbas Basya I, Muhammad Said Basha, Ismail Basha, Taufiq Basha, Abbas Hilmi Il, Raja Fuad, dan Raja Farouk, Al Azhar menghadapi upaya penyempitan dan pembatasan peran politik, agama, dan pendidikan, dengan melalui dua cara, yaitu undang-undang dan menghapus kemandirian finansial Al Azhar (Majidah, t.t.: 287). Pasca revolusi 1952 yang dipimpin oleh perwira militer, Al Azhar sebagai institusi secara total diatur dan diintervensi oleh rezim penguasa, baik terkait urusan akademik, finansial, maupun sikap dan pandangan-pandangan Al Azhar terhadap permasalah-permasalahan sosial, khususnya yang menyangkut urusan politik yang memiliki kepentingan dengan penguasa. "Rezim Juli 1952" menempuh tiga cara untuk menguasai dan mengontrol Al Azhar, yakni melalui undang-undang reformasi tanah (land reform law tahun 1952) di mana dengan aturan ini, seluruh tanah wakaf Al Azhar diambil alih oleh pemerintah (Moustafa, t.t.: 4-5). Tahun 1955, "Rezim Juli" mengeluarkan undang-undang menghapus Mahkamah Syariah sebagai strategi memangkas peran Al Azhar (Munib, 2010:39), dan terakhir adalah undang-undang nasionalisasi Al Azhar pada tahun 1961, di antara poinnya adalah jabatan Grand Syaikh Al Azhar (GSA) ditunjuk oleh presiden (Majidah, t.t.:302).

Kontrol penuh pemerintah terhadap instusi Al Azhar ini kemudian berdampak pada sikap dan pandangan-pandangan Al Azhar, yang lebih condong menyesuaikan dengan pandangan penguasa, termasuk sikap Al Azhar terhadap gerakan-gerakan Islam pada masa Gamal Abdel Nasser. Mereka memiliki sikap yang sama dengan Abdel Nasser yang berkonfrontasi dengan Ikhwan Al Muslimin (IM). Saat itu, Syaikh Al Azhar, Syaikh Abdul Rahman Taj, mengeluarkan pernyataan yang menyerang IM. Sikap yang sama juga terjadi pada masa Anwar Sadat dan Husni Mubarak (Majidah, t.t.:302).

Pasca kudeta terhadap Presiden Mursi 2013 lalu, sejumlah ulama Al Azhar menyerang IM, di antaranya, Syaikh Usamah Al Azhary yang menulis buku al-Haq al-Mubin, di mana dalam buku tersebut IM disebut sebagai gerakan radikalis dan disamakan dengan ISIS. Namun menurut Muhammad Imarah, fenomena seperti ini 
bukanlah hal baru karena di tahun 1961 hal yang sama pernah terjadi, yaitu ketika sejumlah ulama Al Azhar menyebut IM sebagai Ikhwan al-Syayathin. Hal ini terjadi karena tekanan rezim penguasa kepada ulama-ulama Al Azhar, dan institusi agama menjadi bagian dari negara (wawancara dengan Imarah, 20 September 2016).

Dari tahun 1928 hingga 1942, IM menjalankan segala aktivitasnya dengan bebas, dan mulai fase setelah 1942-an, hubungan IM dengan rezim penguasa mengalami ketegangan yang berakhir dengan pembubaran IM. Saat itu seluruh kader-kadernya mengalami penindasan, penangkapan, pemenjaraan, penyiksaan, dan berbagai unit usaha IM mengalami pembredelan (Shammakh, 2011: 3). Masa-masa berikutnya, pola hubungan IM dengan penguasa memiliki pola yang sama, dimulai melalui pola relasi akomodasi atau aliansi, kemudian berakhir dengan konfrontasi. Raja Farouk mengakomodasi IM dari 1942-1947 dan setelahnya menindas IM hingga 1952. Nasser mengakomodasi IM pada 1952, namun tidak lama setelah itu, terjadi konfrontasi dan perbedaan pandangan dengan IM dan menindasnya hingga 1970. Pola hubungan yang sama terjadi pasca-Nasser, ketika Anwar Sadat muncul sebagai patron kebangkitan Islam di Mesir. Sadat awalnya merehabilitasi posisi IM dan berperan sebagai pelindung organisasi mahasiswa Islam (Esposito, 1994:145). Namun kemesraan itu tidak berlangsung lama. IM menyerang kebijakan Anwar Sadat yang mengambil langkah kontroversial dengan menandatangani perjanjian damai dengan Israel pada 1979 (Dzakirin, 2015:89). Konflik antara Sadat dan IM berlanjut hingga akhirnya Sadat terbunuh tahun 1981 (Dzakirin, 2015:58).

Pasca terbunuhnya Anwar Sadat pada tanggal 6 November 1981, jabatan Presiden kemudian beralih ke Husni Mubarak. Langkah pertama yang ditempuh Mubarak adalah melakukan rekonsiliasi dengan IM dan kelompok-kelompok di luar IM. Mubarak pun membebaskan tahanan di masa Sadat serta memberikan ruang kebebasan berpendapat dan berekspresi bagi seluruh kalangan. Ini yang kemudian menyebabkan aktivitas IM kembali aktif, dan pada Januari 1983, Kantor Pusat IM diresmikan (Shammakh, 2013: 28). Namun di akhir tahun 1992, benturan antara IM dan rezim Mubarak mulai terjadi, yang dikenal di media sebagai kasus "Salsabil" di mana IM dituduh kembali menghidupkan tandzim-nya yang dinyatakan ilegal oleh pemerintah. Kasus ini menyebabkan sejumlah petinggi IM ditangkap, di antaranya Khaerat Syatir, Hasan Malik, Mahmoud Izzat, dan Muhyiddin Hamid.

IM kemudian terus mengalami bentuk-bentuk penindasan berupa tekanan, penangkapan, pengusiran, hukuman militer, penahanan sementara, pemberedelan, dan perang terhadap sumber-sumber penghasilan IM dan sebagainya. Penjara Husni Mubarak selalu dipenuhi oleh puluhan, ratusan, bahkan ribuan kader-kader IM, 
terlebih di masa-masa ketika IM memutuskan untuk ikut dalam pemilihan parlemen (Al Anani, 2013). Era Mubarak tahun 2000-2011 merupakan masa-masa terburuk bagi IM karena pada rentang sepuluh tahun tersebut jumlah anggota IM yang ditangkap lebih 30 ribu orang dan ribuan perusahaan pribadi anggota IM dijarah (Shammakh, 2013:36). Begitu pun di masa awal revolusi 25 Januari 2011, The Supreme Council of the Armed Forces (SCAF), atau dalam bahasa Arab al-Maglis al-'A'lā lil-Quwwāt alMusallaha, di bawah kepemimpinan Jenderal Al Sisi, yang semula mengakomodasi IM berbalik menindasnya sejak kudeta 2013 hingga sekarang.

\section{Respon Al Azhar dan Ikhwan Al Muslimin Terhadap Revolusi 2011}

Di masa-masa berlangsungnya Revolusi 25 Januari 2011, Al Azhar melalui GSA (Grand Syaikh Al Azhar) sama sekali tidak memberikan respon atas aksiaksi demonstrasi yang berlangsung. Baru setelah Presiden Mubarak lengser, GSA mendukung revolusi tersebut dan menyebut korban yang meninggal selama revolusi sebagai martir revolusi (Syuhada al-Tsaurah), juga menyebut revolusi sebagai revolusi putih bersih (Farag, 2011:60).

Sejak awal munculnya seruan melakukan demonstrasi dan aksi massa di Mesir awal tahun 2011 dan menjadikan tanggal 25 Januari (hari ulang tahun kepolisian Mesir) sebagai momentum awal, Al Azhar belum mengeluarkan sikap resmi. Bahkan sebagian pihak telah memprediksi sikap yang bakal dikeluarkan Al Azhar adalah sikap umum terkait "kebebasan mengemukakan pendapat" dan seruan "damai dalam berdemonstrasi" dan prediksi penegasan kepercayaan dan keyakinan pada kepemimpinan pemerintahan Presiden Husni Mubarak dan pemimpin-pemimpin keamanan (wawancara dengan Habib, 21 September 2016).

Sejak tanggal 25 Januari 2011, situasi dan esklasi demonstrasi semakin memanas hingga tiga hari berturut-turut, dan tepatnya pada tanggal 28 Januari yang disebut sebagai hari Jumat Amarah "Jum'ah al-Gadhab" menjadi salah satu penentu keberhasilan Revolusi 25 Januari. Pada masa itu, majalah Al Azhar yang menjadi suara resmi Al Azhar baik sebagai lembaga pendidikan dan Masjid Al Azhar menunjukkan keberpihakan pada pemerintah dan kepolisian dengan memberikan ucapan selamat kepada Menteri Dalam Negeri Mesir Habib al-Adli dan memasang fotonya dalam ukuran besar.

Selanjutnya, otoritas resmi Al Azhar mengeluarkan mengeluarkan imbauan kepada para mahasiswa untuk tidak ikut terlibat dalam demonstrasi di Lapangan Tahrir. GSA, Dr. AhmadThayyib, memberikan pernyataan resmi, menyebut aksi protes 
sebagai illegitimate in Islam (tidak sah dalam Islam) dan meminta para demonstran untuk pulang. Alasan yang dikemukakan, demosntrasi di Tahrir adalah melanggar syariah, tidak taat kepada pemimpin, dan menimbulkan fitnah. Pernyataanpernyaatan dan fatwa yang mengharamkan demonstrasi secara khusus ditulis dan dibantah oleh Dr. Ahmad Rasuni dalam bukunya Figh al-Ihtijaj wa al-Taghyir dengan judul Wujub Azl ar-Rais al-Masri wa Muhakamatih (Wajibnya Melengserkan Presiden Mesir [Husni Mubarak] dan Menghukumnya).

Sikap defensif dan cenderung memberikan legitimasi bagi keberlangsungan rezim ini menimbulkan friksi di kalangan internal Al Azhar. Beberapa guru besar menolak mengikuti instruksi lembaga rektorat untuk diam dan tidak mengeluarkan pernyataanapapun selama pergolakan politikdi Mesir terjadi. Reaksikeras ditunjukkan oleh Muhammad Rafi al-Tahtawi, juru bicara resmi Al Azhar, yang mengundurkan diri dari jabatannya dan bergabung dengan demonstran di Lapangan Tahrir. Salah satu tokoh penting dalam Dewan Fatwa Al Azhar, Syaikh Emad Effat, kemudian tewas terbunuh di Lapangan Tahrir.

Lembaga Al Azhar baru menunjukkan sikap dan melakukan langkah-langkah pro revolusi, seperti menjadikan lembaga tersebut sebagai tempat pertemuan para perwakilan pemuda revolusioner, melakukan pendekatan perspektif, dan melindungi negara dari kekacauan, pasca peristiwa yang dikenal dengan Perang Jamal (Mauqiatul Jamal) pada tanggal 2 Februari 2011. Dr. Thayyib kemudian pada tanggal 3 Februari 2011 mengeluarkan pernyataan yang menyeru para pemuda revolusi untuk "menggunakan akal sehatnya", yang mana menurutnya peristiwa yang terjadi di Mesir bertujuan untuk memecah belah dan melaksanakan agenda luar negeri. Dr. Thayyib juga mempertanyakan di mana suara-suara para pemikir. Dia juga menyeru pemuda untuk kembali ke rumah mereka dan menenangkan situasi dan mengusulkan untuk memilih sekelompok perwakilan pemuda untuk berdiskusi dengannya untuk membahas solusi krisis, agar memiliki persepsi yang sama.

Peristiwa penting yang terjadi pada tanggal 3 Februari adalah pengunduran diri juru bicara resmi Mashikhah Al Azhar Muhammad Rifaah al-Thahthawi dari jabatannya dan mengumumkan bergabung dengan demonstran yang melakukan sit in di Lapangan Tahrir. Rifaah Thahthawi juga berjanji akan mendukung revolusi dengan segala kekuatannya hingga lengsernya Presiden Mubarak. Ini adalah satusatunya respon nyata dari salah seorang yang memiliki jabatan tinggi di Lembaga Al Azhar yang secara penuh mendukung revolusi. Pengunduran Rifaah Thahthawi ini tidak mendapat respon apa-apa dari Lembaga Al Azhar. 
Pada tanggal 9 Februari 2011, atau dua hari sebelum lengsernya Presiden Husni Mubarak, Syaikh Al Azhar mengeluarkan pernyataan, bahwa tidak taat kepada pemerintah (penguasa) adalah haram secara syariat dan "barangsiapa yang menyeru revolusi atau menuruti seruan revolusi maka baginya adalah neraka". Pernyataan itu disampaikan Dr. Thayyib melalui televisi pemerintah. Namun akhirnya, Presiden Mubarak mengundurkan diri. Klarifikasi yang diberikan Dr. Thayyib atas pernyataannya sebelumnya adalah demi menjauhkan massa dari pertumpahan darah dan untuk menenangkan situasi dan kondisi. Pasca lengsernya Presiden Mubarak, GSA mengeluarkan pernyataan yang menyebut korban yang meninggal selama revolusi sebagai martir revolusi (Syuhada al-Tsaurah) dan menyebut revolusi sebagai revolusi putih bersih (Emad, 2013:50).

Sebaliknya, Ikhwan Al Muslimin (IM) mendukung penuh revolusi yang berlangsung sejak 25 Januari hingga lengsernya Mubarak pada tanggal 11 Februari 2011. Dua hari sebelum meledaknya Revolusi 25 Januari, yaitu pada 23 Januari 2011, IM mengeluarkan pernyaatan resmi sebagai respon atas ancaman yang disampaikan rezim Mubarak. Dalam pernyataannya, IM menegaskan tidak akan meninggalkan rakyat dan tidak rela menjadi alat rezim, dan IM tidak takut dengan dengan ancaman tersebut (Shammakh, 2011:25). IM juga menyusun 11 strategi untuk mempertahankan dan mendukung revolusi.

Pasca Revolusi 25 Januari, hubungan IM dan GSA pun mulai terjalin, ditandai dengan kunjungan pimpinan IM ke kantor GSA pada tanggal 3 Mei 2011. Dalam kunjungan tersebut sejumlah petinggi IM hadir, di antaranya Mursyid IM, Muhammad Badie; mantan Mursyid IM, Mahdi Akib; dua guru besar ilmu Hadits Al Azhar dan Mufti IM, Syaikh Abdul Rahman al-Barr dan Syaikh Sayyid Askar; Asisten Sekertaris Majma' al-Buhuts al-Islamiyah; dan anggota dewan syuro IM (Ikhwanwiki, 2016).

\section{Al Azhar, Ikhwan Al Muslimin, dan Kudeta Militer 2013}

Melalui pemilu demokratis pertama di Mesir pada November 2011 dan Januari 2012, Partai Keadilan dan Kebebasan (Hizb al-Adalah wa al-Huriyah) atau sering disingkat FJP, bentukan Ikhwan Al Muslimin (IM), memenangi pemilu dengan perolehan suara yang meyakinkan (landslide victory). FJP memperoleh suara 47,2 \% (235 dari 508 kursi), disusul Partai Salafi an-Nur yang memperoleh kursi 123 (24,3\%), sehingga kubu Islamis menguasai 73 \% total kursi parlemen (Shammakh, 2011:26).

Pada pemilihan presiden putaran pertama, Muhammad Mursi (kandidat sipil yang didukung IM) meraih suara terbanyak, kemudian disusul oleh Jenderal Ahmad 
Syafiq (kandidat yang didukung kubu militer) dengan selisih yang sedikit. Urutan ketiga diduduki Hamdan Shabbahi, kemudian Abol Futuh pada urutan keempat, dan Amr Musa berada di urutan kelima. Muhammad Mursi meraih suara lebih 5 juta suara dan merepresentasikan 50\% pencapaian IM pada pemilihan parlemen 6 bulan sebelumnya (Habib, 2013:46). Pada 14 Juni 2012, pemilihan presiden Mesir putaran kedua berlangsung, antara Ahmad Syafiq dan Muhammad Mursi. Hasil pemilihan presiden putaran kedua dimenangkan oleh Mursi. la menang tipis, medapatkan suara $51,7 \%$ sementara Syafiq yang merupakan mantan perdana menteri pada era Mubarak mendapat suara sebanyak 48,8\% (Dzakirin, 2015:297).

Jelang setahun masa pemerintahan Mursi, pada tanggal 26 April 2013, berdiri gerakan pemberontakan Tamarod (atau Tamarrud) yang disebut-sebut didirikan oleh intelejen SCAF (The Supreme Council of the Armed Forces) dan ditugaskan untuk mengumpulkan tanda tangan rakyat Mesir untuk mendeklarasikan mosi tidak percaya kepada Presiden Mursi, dan menuntut percepatan pemilihan persiden. Gerakan Tamarod mengklaim telah mengumpulkan 22 juta tanda tangan dan menjatuhkan mosi tidak percaya pada Presiden Mursi, dan mengajak orang-orang yang menandatangani mosi itu untuk melakukan demonstrasi pada tanggal 30 Juni 2013 (fi-p.com, 2016).

Demonstrasi ini kemudian oleh kelompok oposisi disebut sebagai "Revolusi 30 Juni" yang menyerupai nama Revolusi 25 Januari 2011 yang melengserkan Husni Mubarak. Sementara kubu pendukung Mursi juga melakukan aksi yang sama, mengumpulkan 26 juta tandatangan pendukung Mursi yang disebut dengan aksi Tajarrud, lawan dari Tamarrud. Tuntutan oposisi kemudian disambut oleh SCAF, di mana keesokan harinya yaitu tanggal 1 Juli 2013 SCAF memberikan ultimatum kepada pemerintah dan pihak oposisi agar segera menyelesaikan konflik dan kerusuhan yang terjadi di hampir seluruh wilayah Mesir. SCAF mengultimatum, jika dalam waktu 48 jam kerusuhan dan konflik tidak mereda, militer akan melakukan intervensi (Aljazeera, 2013). Sore 3 Juli, militer Mesir melalui kepala SCAF, Jenderal Abdul Fatah al-Sisi secara resmi mengumumkan bahwa Mursi tidak lagi memiliki jabatan sebagai presiden dan berubah status menjadi tahanan rumah, konstitusi ditangguhkan, pemilihan presiden baru akan diadakan, dan Ketua Mahkamah Konstitusi, Adly Mahmoud, akan mengambil alih sementara istana presiden (The Guardian, 2013).

Kudeta militer yang terjadi pada hari Rabu 3 Juli 2013 itu telah melengserkan Presiden yang dipilih melalui pemilu demokratis, Muhammad Mursi. Dalam menyikapi kejadian ini, Al Azhar terlihat memberikan dukungannya melalui sejumlah langkah, 
antara lain pernyataan dan pidato Syaikh Al Azhar yang menggunakan kaidah syari' yaitu irtikab akhaffu al-dhararain atau mengambil bahaya yang lebih ringan dari dua bahaya; kaidah inilah yang dijadikan landasan hukum untuk mendukung kudeta (Almasrialyoum, 2016).

Tahapan selanjutnya, yaitu pada Rabu 24 Juli 2013, Jenderal Abdel Fattah AI Sisi meminta rakyat Mesir untuk turun ke jalan pada hari Jumat, dua hari kemudian, guna memberikan legitimasi (tafwîdh) kepada militer dan polisi dalam menghadapi apa yang disebut sebagai "kekerasan dan kemungkinan teror". Dalam pidatonya pada wisuda akademi militer, Al Sisi mengatakan, "Saya meminta orang-orang Mesir hari Jumat, semua orang Mesir yang mulia yang amanah, untuk turun demi memberikan kepada saya dukungan legitimasi dan perintah menyelesaikan kekerasan dan terorisme." (Alhurra, 2013).

Syaikh Thayyib menanggapi seruan tersebut dengan mengatakan, "Al Azhar sangat yakin bahwa ajakan untuk keluar berkumpul pada hari Jumat, seperti yang dijelaskan oleh Juru Bicara SCAF, adalah panggilan bagi seluruh rakyat Mesir untuk bersatu dan saling membahu menghilangkan anarkisme dan kebencian." Al Azhar kemudian secara nyata memberikan dukungan kepada militer dan polisi dan seluruh lembaga-lembaga negara untuk menghadapi segala bentuk kekerasan, terorisme, dan bahaya yang akan menimpa Mesir (Alhurra, 2013).

Sikap dan pidato GSA ini kemudian dikritisi oleh Syaikh Yusuf Al Qardhawi, mantan anggota Majma al-Buhuts al-Islamiyah Al Azhar yang kemudian mengundurkan diri dari keanggotannya pasca dukungan Syaikh Al Azhar terhadap kudeta tanpa melibatkan musyawarah dari ulama Al Azhar (Majma' al-Buhuts) (Alarab, 2013). Dalam tulisannya yang berjudul yang berjudul Waqafât Ma'a Syaikh al-Azhâr wa Qadhiyah al-Inqilâb ala al-Syar'iyah, Syaikh Yusuf AI Qaradhawi menulis:

Pidato Anda kepada rakyat Mesir, setelah pidato kudeta AI Sisi, adalah dukungan atas kejahatannya, dukungan atas tindakan dan upayanya, penyambung agar rakyat menerimanya. Lalu, apa yang Anda telah lakukan dengan menyetujui penggulingan Mursi itu adalah penggulingan yang syar'i dan legitimate wahai Syaikh Al Azhar. Padahal Anda tahu bahwa Dr. Mursi adalah presiden syar'i dan legitimate yang terpilih secara bebas, menaatinya masih kewajiban bagi Anda juga bagi Al Sisi. Dan ini yang telah diperintahkan oleh Allah dan Rasul-Nya dan juga telah diwajibkan oleh kaidah dan prinsip dan hukum-hukum syariat juga diwajibkan oleh kepentingan masyarakat umum (www.raissouni.ma, 2013). 
Pasca kudeta militer, kelompok IM dan pendukung Mursi melakukan aksi demonstrasi besar-besaran di berbagai lapangan di Mesir, utamanya di lapangan Masjid Rabiah Al Adaweah, Al Nahdhah Universitas Kairo, dan tempat-tempat lainnya di berbagai provinsi Mesir. Pendukung Mursi juga membentuk aliansi nasional pendukung legitimasi al-Tahaluf al-Wathani Lida'am al-Syariyah. Militer merespon aksi bertahan pendukung Mursi dengan kekerasan yang mengakibatkan jatuhnya ribuan jiwa rakyat Mesir di lapangan Rabiah (BBC, 2018). Penolakan IM terhadap kudeta militer di Mesir pun terus berlanjut hingga saat ini walaupun tidak lagi menggunakan cara-cara demontrasi turun ke jalan.

Dengan demikian, dalam hal ini IM dan AI Azhar menunjukkan sikap politik yang sangat berbeda dalam menyikapi kudeta militer yang dilakukan oleh AI Sisi. Al Azhar sebagai lembaga keagamaan di Mesir menggunakan justifikasi hukum agama dalam memberikan dukungan kepada penguasa, dengan argumentasi 'memilih kerusakan atau bahaya yang lebih sedikit di antara dua bahaya', sedangkan IM menunjukkan secara tegas melakukan perlawanan terhadap kudeta militer yang menggulingkan presiden yang terpilih melalui proses demokratis.

Perbedaan pandangan ini antara lain terjadi karena sistem kekuasaan di Mesir yang tersentralisasi dan tidak memberikan ruang bagi kelompok-kelompok oposisi untuk bebas menyaingi partai penguasa dalam pemilu. Adanya tekanan demokratisasi dari dunia internasional terkadang membuat penguasa otoriter Mesir menciptakan pseudo-demokrasi, formalitas pemilu, yang hasil dan pemenangya sudah diketahui.

Bila kita mengimplementasikan teori konflik Dahrendorf, Al Azhar dapat dipandang sebagai lembaga yang memiliki otoritas yang cukup besar di tengah masyarakat dan berkepentingan dalam mempertahankan status quo. Di sisi lain, penguasa (dalam hal ini kubu militer Mesir) sebagai pemilik otoritas yang lebih kuat juga berkepentingan menjaga kekuasaannya agar tetap langgeng. Dalam kasus Mesir, penguasa Mesir melemahkan kekuatan persatuan masyarakat dengan menciptakan dan mempertahankan friksi dan pertentangan di tengah berbagai kelompok dalam masyarakat. Sebagian kelompok yang memiliki otoritas (misalnya, dalam kasus ini, lembaga Al Azhar) berupaya ditarik masuk ke dalam pusaran kekuasaan, sementara sebagian kelompok lainnya (dalam hal ini, IM) mengalami diskriminasi atau bahkan penindasan. Akibatnya, masyarakat tidak memiliki satu titik persatuan (kepentingan bersama) yang bisa menjadi kunci integrasi masyarakat. 
Untuk itu, penulis merekomendasikan pentingnya dibangun sistem baru yang terlepas dari kekuatan penguasa otoriter, yaitu sistem yang secara demokratis memberikan peluang dan kebebasan kepada setiap elemen masyarakat untuk mengajukan format dan bentuk sistem yang dikehendaki. Perbedaan-perbedaan pendapat yang ada di tengah masyarakat perlu dipandang sebagai kekayaan yang harus dikelola dengan semangat persatuan. Bila tidak, sebagaimana sudah terjadi, perbedaan pendapat dalam fase transisi Mesir justru dimanfaatkan oleh jaringan rezim lama untuk menggagalkan agenda-agenda Revolusi 25 Januari 2011.

\section{Kesimpulan}

Al Azhar dan Ikhwan Al Muslimin adalah dua institusi sosial yang sangat mempengaruhi kondisi sosial dan demokrasi di Mesir. Secara pemikiran dan manhaj, kedua institusi ini menganut ideologi moderat dan keduanya tidak dapat dipisahkan karena sama-sama menghendaki perubahan ke arah kemajuan Mesir. Ulama-ulama Al Azhar yang menginginkan transformasi (al-Azhariyun al-Mujaddidun) mayoritasnya menjadikan IM sebagai gerakan perubahan.

Namun dalam perjalanan sejarahnya, intervensi yang dilakukan negara terhadap institusi Al Azhar membuat lembaga ini terlibat dalam percaturan politik dan khususnya dalam konflik antara negara dengan IM, Al Azhar cenderung kehilangan independensinya. Sebagaimana diuraikan dalam pembahasan artikel ini, terlihat bahwa hubungan antara AI Azhar dan IM sangat dipengaruhi oleh kondisi hubungan antara IM dan rezim penguasa. Dalam konflik di Mesir pasca kudeta militer 2023, Al Azhar sebagai pemilik otoritas keagamaan menggunakan otoritasnya dengan alasan demi menjaga stabilitas, namun di saat yang sama juga berarti menjaga status quo pemerintahan yang didukung militer.

\section{Daftar Pustaka}

Wawancara dengan Muhammad Imarah, Kairo, Mesir, 20 September 2016.

Wawancara dengan Rafiq Habib, Kairo, Mesir, 21 September 2016.

Basyar, M. H. (2015). Pertarungan dalam Berdemokrasi: Politik di Mesir, Turki dan Israel. Jakarta: UI-Presss. 
BBC. (2018). Egypt sentences hundreds over 2013 pro-Morsi protests. [Online] Dalam https://www.bbc.com/news/world-middle-east-45457935 [Diakses 15 Desember 2019]

Dzakirin, A. (2015). 8 Dekade Pergulatan Politik Ikhwan Al Muslimin Menuju Kekuasaan, Surakarta: Media Insani.

Esposito, J. L. (1999). Demokrasi di Negara-Negara Muslim, (pent. Armanani Astuti), Mizan: Bandung.

Emad, A. G. (2013). al-Islamiyûn Baina al-Tsaurah wa al-Daulah, Isykaliyah Intaj alNamudzaj wa Bina al-Khitâb (Islamists between Revolution and State Problematic of Producing the Model and Building the Discourse), Beirut: Markaz Dirâsat al-Wahdah al-Arabiyah.

Farag, M. (Cet. 2, 2011) Tsaurah Sya'b 25 Yanair, Haqaiq Alu Mubârak wa al-Wuzarâ, Kairo.

Hasan, A. A. (1995) al-Ishlâh al-Siyâsi fi Mihrâb al-Azhâr wa al-lkhwân al-Muslimîn, Kairo: Markaz al-Qâhirah Lidirâsât Huqûq al-Insân.

Khafaji, A. H. (2006) Indama Gâbat al-Syams, Kairo: Dâr al-Nasr wa al-Tauzi'.

Majidah, Shalih Ali. (t.t.). al-Azhâr fi Qarn.

Mamdud, R. (2018). Genealogy of Moslem Brotherhood dan AI Qaida in the Middle East. Jurnal ICMES, 2(1), 48-68. https://doi.org/10.35748/jurnalicmes.v2i1.15

Munib, A. M. (2010) Dalîl al-Harakah al-Islâmiyah al-Masriyah. Kairo: Maktabah Madbouli.

Ritzer, George (2008). Teori Sosiologi Modern. (Terjemahan oleh Alimandan). Jakarta: Kencana Prenada Media.

Rashed, S. (2016). Ifta' al-Masyaikh fi al-Siyasah. Al Araby [online] Dalam: https:// www.alaraby.co.uk/opinion/2016/2/21/\%D8\%A5\%D9\%81\%D8\%AA\%D8\%A7 \%D8\%A 1-\%D8\%A7\%D9\%84\%D9\%85\%D8\%B4\%D8\%A7\%D9\%8A\%D8\%AE\%D9\%81\%D9\%8A-\%D8\%A7\%D9\%84\%D8\%B3\%D9\%8A\%D8\%A7\%D8\%B3 \%D8\%A9 [diakses 15 Desember 2019]

Shammakh, A. (2011). Ikhwan Al Muslimin Siapa Kami dan Apa yang Kami Inginkan?, (Pent. Muhammad Anas), Yogyakarta: Era Intermedia. 
Shammakh, A. (2013) al-Ikhwân al-Muslimûn wa Tsaurah 25 Yanâir, Kairo: Dâr al-Tauzì wa al-Nasr.

Moustafa, T. (t.t.). Confilct and Cooperation Betwen The State and Religius Institution in Contemporary Egypt.

Al Anani, K. (2011). Aljazera Center for Studies, Mubârak wa al-lkhwân, Khibrah al-Tsalâtsina Âman. Dalam: http://studies.aljazeera.net/ar/fil es/2011/08/201187113648385131.html [Diakses 1 Desember 2019]

Aljazeera. (2013). al-Sisi Yathlubu Khurûj al-Syari' Limuwajah "al-Irhâb". [Online] Dalam http://goo.gl/c4rwqW [Diakses 1 Desember 2019]

Alarab. (2013). Al-Qardhawy Yastaqilu min Haiah Kibar al-Ulamâ bi al-Azhâr Ihtijâjan Ala Mauqifi Ahmad al-Thayyib. [Online] Dalam: http://www.alarab.com/ Article/577515 [Diakses 1 Desember 2019]

Alhurra (2013), Syaikh al-Azhâr Yahutsu al-Masriyiin ala Talbiyah Dakwah al-Sîsi ala alTadzâhur. [Online] Dalam http://www.alhurra.com/a/muslim-brotherhood-callspeaceful-protests/227904.html [Diakses 1 Desember 2019]

Almasrialyoum. (2016). al-Imâm al-Akbar: Irtikâb Akhaffu al-Dharârain Wâjibun Syar'i. [Online] Dalam http://www.almasryalyoum.com/news/details/475056 [Diakses 1 Desember 2019]

f-p.com [Situs resmi Partai Kebebasan dan Keadilan-FJP]. (2016). Khafâya wa Asrâr Inqilâb 30 Yuni al-Amrîki. [Online] Dalam http://www.fj-p.com/headline_Details. aspx?News_ID=97668 [Diakses 26 Juni 2016]

raissouni.ma. (2013). Waqafât Ma'a Syaikh al-Azhâr wa Qadhiyah al-Inqilâb ala alSyar'iyah. Dalam http://raissouni.ma/index.php/articles/531/531.html [Diakses 13 Juli 2016]

Ikhwanwiki.com, situs resmi sejarah Ikhwan Al Muslimin [Diakses 13 Juli 2016]

Theguardian.com. (2013). [Online] Dalam https://www.theguardian.com/world/ middle-east-live/2013/jul/03/egypt-countdown-army-deadline-live [Diakses 1 Desember 2019] 